\title{
Non-Specific Mesenteric Lymphadenitis and Cervical Lymphadenopathy in Pediatric Age Group - A Correlative Study
}

\author{
Nagaraj Murthy ${ }^{1}$, Rajesh Raman ${ }^{1}$ \\ 'Department of Radiology, JSS medical college hospital, Mysore.
}

Abstract

Background: The aim of the study is to assess the correlation between non-specific mesenteric lymphadenitis in children with cervical lymphadenopathy. Subjects and Methods: Total of 172 cases with Ultrasound features of non-specific mesenteric lymphadenitis reported in Department of Radiology, JSS medical college hospital, Mysore during the period of October 2016 \& July 2018 were included in the study and correlated with Ultrasound of the neck. The clinical profile and attributed causes of these cases were correlated and evaluated. Results: Out of 172 cases, $60.5 \%$ of cases presented with pain abdomen being the most common symptom. Upper respiratory symptoms were noted in $37.2 \%$ of cases, diarrhea in $6.4 \%$ cases, urinary tract symptoms in $3.5 \%$ and fever in $18.6 \%$ of cases. Cervical adenopathy was noted in 72 cases (41.9\%) of total cases out of which 55 cases had signs of upper respiratory tract infection. Conclusion: Ultrasound diagnosis of non specific mesenteric lymphadenitis is important to differentiate it from other causes of pain abdomen. Upper respiratory tract infection is one of the most common causes of non specific mesenteric adenitis and is associated with cervical adenopathy.

Keywords: Non specific mesenteric lymphadenitis, cervical adenopathy, Ultrasound.

Corresponding Author: Dr.Rajesh Raman, Department of Radiology, JSS Medical college, Mysore.

Received: September 2018

Accepted: September 2018

\section{Introduction}

Mesenteric adenitis is described as three or more lymph nodes measuring $5 \mathrm{~mm}$ or greater, present in the right lower quadrant mesentery. Without any detectable cause it is considered primary/ non-specific and if specific cause is detected, then it is considered secondary. ${ }^{[1]}$

Non specific mesenteric lymphadenitis is a well documented condition with no clear etiology / pathogenesis. Wilensry and Hahn described the mesenteric lymphatic system and stated that the mesenteric lymph nodes had the same functional relationship to Peyer's patches of the ileum, as the cervical lymph nodes have to the tonsil and adenoidal tissue of the nose and throat. $^{[2]}$ Mesenteric lymphadenopathy was thought to be due to tuberculosis in the earlier days and with advancements in newer diagnostic methods, other organisms were also found to be etiologically equal or more important. ${ }^{[3]}$ The association of abdominal pain and upper respiratory tract infections in children was suggested by Brenneman as well as by Goldberg and Nathanson. ${ }^{[4,5]}$ Mesenteric lymphadenitis is often associated with adenoviral infection and adenovirus is one of the most common cause of tonsillitis. ${ }^{[6,7]}$ "Mesenteric lymphadenitis is associated with findings such as swollen cervical lymph nodes' was stated by Rosanna helbling et al. ${ }^{[8]}$
This process may be acute or chronic, depending on the causative agent, and it causes a clinical presentation that is often difficult to differentiate from acute appendicitis, particularly in children. ${ }^{[1,9-12]}$

Laparoscopy was used to differentiate between appendicitis \& non specific mesenteric adenitis till recently. With improvement of Ultrasound technology and technique, the diagnosis of non specific mesenteric adenitis is the forte of Radiologist. Ultrasound is widely used as a screening and diagnostic tool in cases of abdominal pain. It is noninvasive, quick and reliable method to exclude most of the causes of abdominal pain.

The diagnosis of abnormal lymph node mainly depends on size criteria and the short-axis diameter of less than or equal to $4 \mathrm{~mm}$ is considered normal mesenteric lymph node size. ${ }^{[13,14]}$ Mesenteric lymph nodes are considered to be enlarged, when the short-axis crosses $8 \mathrm{~mm} .{ }^{[15]}$ Location of mesenteric lymph nodes may indicate the nature of underlying disease process. ${ }^{[16]}$

In most cases of non specific mesenteric lymphadenitis reported, enlarged nodes were noted in the ileo-caecal region. ${ }^{[16-18]}$ In cases of acute abdominal pain with enlarged mesenteric lymph nodes and no other pathology detected on Ultrasound, the most probable diagnosis would be nonspecific mesenteric adenitis. ${ }^{[1]}$ 


\section{Subjects and Methods}

All consecutive cases of sonologically diagnosed Nonspecific mesenteric adenitis, in the Department of Radiology, JSS medical college hospital, Mysore during the period of October 2016 \& July 2018 were included in the study. Proper informed consent was taken from all patients included in the study and ultrasound of neck was performed in the same sitting. Total of 172 cases aged between $3 \mathrm{yrs}$ and $18 \mathrm{yrs}$ were included in the study. All cases of paraaortic / retro-peritoneal adenopathy as well as known cases of HIV and neoplastic lesions were excluded from the study. Clinical history, signs and symptoms, lab reports and chest $\mathrm{X}$-ray findings were recorded for all the patients included in the study. Three or more mesenteric nodes in the RIF, measuring more than $8 \mathrm{~mm}$ was considered positive for nonspecific mesenteric adenitis. Any station node measuring more than $10 \mathrm{~mm}$ was considered enlarged for cervical lymphadenopathy.

\section{Results \& Discussion}

In our study the most common age group affected with Nonspecific mesenteric adenitis was $7 y$ rs to $12 \mathrm{yrs}$ and the second most commonly involved group was $13 y$ rs to 18yrs.[Table 1]

\section{Table 1: Shows age group affected.}

\begin{tabular}{|c|c|c|}
\hline Age & Numbers & Percentage \\
\hline 3-6yrs & 25 & $14.5 \%$ \\
\hline 7-12yrs & 117 & $68.0 \%$ \\
\hline 13-18yrs & 30 & $17.4 \%$ \\
\hline
\end{tabular}

Out of the 172 cases 110 were males, making up $64 \%$ of the cases and $36 \%$ of the affected cases were females. [Table 2]

Table 2: Shows the sex distribution of Non-specific mesenteric adenitis.

\begin{tabular}{|c|c|c|}
\hline Sex & Number & Percentage \\
\hline Female & 62 & $36 \%$ \\
\hline Male & 110 & $64 \%$ \\
\hline
\end{tabular}

The most common presentation was pain abdomen, which was seen in 104 cases making up $60.5 \%$ of the total. Second most presenting symptom was upper respiratory tract infection, which was noticed in 64 cases, making up $37.2 \%$ of the total number of cases. This was followed by fever, which was present in $18.6 \%$ of the cases. Diarrhea and urinary tract infection symptoms were noted $6.4 \%$ and $3.5 \%$ of the cases, respectively. [Table 3]

Table 3: Shows the most common symptoms associated with
mesenteric adenitis.
\begin{tabular}{|c|c|c|}
\hline Symptoms & Numbers & Percentage \\
\hline Pain abdomen & 104 & $60.5 \%$ \\
\hline $\begin{array}{c}\text { Upper respiratory tract } \\
\text { infection }\end{array}$ & 64 & $37.2 \%$ \\
\hline Diarrhea & 11 & $6.4 \%$ \\
\hline Urinary tract infection & 6 & $3.5 \%$ \\
\hline Fever & 32 & $18.6 \%$ \\
\hline
\end{tabular}

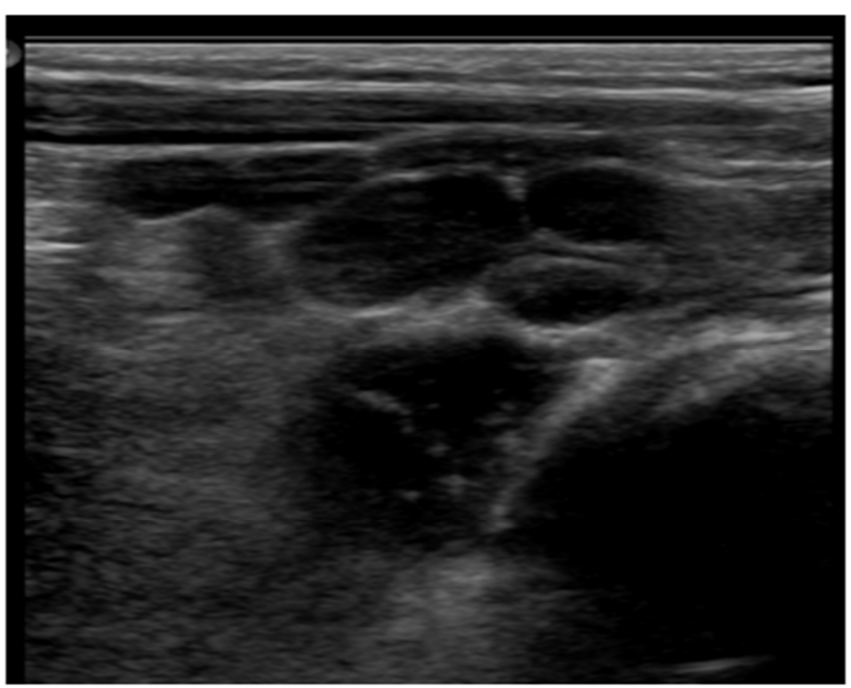

Figure 1: Ultrasound image, shows enlarged lymph nodes in the right iliac fossa.

In our study cervical adenopathy was seen in 72 cases i.e., $41.9 \%$ of the total number of cases. No cervical adenopathy was noted in $58.1 \%$ of the cases.[Table 4]

Table 4: Shows number and percentage of cases having cervical adenopathy.

\begin{tabular}{|c|c|c|}
\hline Cervical adenopathy & Numbers & Percentage \\
\hline Yes & 72 & $41.9 \%$ \\
\hline No & 100 & $58.1 \%$ \\
\hline
\end{tabular}

Out of the 72 cases with cervical adenopathy, 55cases had upper respiratory tract infection symptoms while17 cases had no upper respiratory tract infection symptoms. And 9 cases with upper respiratory tract infection symptoms had no cervical adenopathy.

Table 5: Shows 2x2 table with Confidence interval of 95\%.
\begin{tabular}{|c|c|c|c|}
\hline & $\begin{array}{c}\text { Cervical } \\
\text { adenopathy + }\end{array}$ & $\begin{array}{c}\text { Cervical } \\
\text { adenopathy - }\end{array}$ & Total \\
\hline URTI + & 55 & 9 & 64 \\
\hline URTI - & 17 & 91 & 108 \\
\hline Total & 72 & 100 & 172 \\
\hline
\end{tabular}

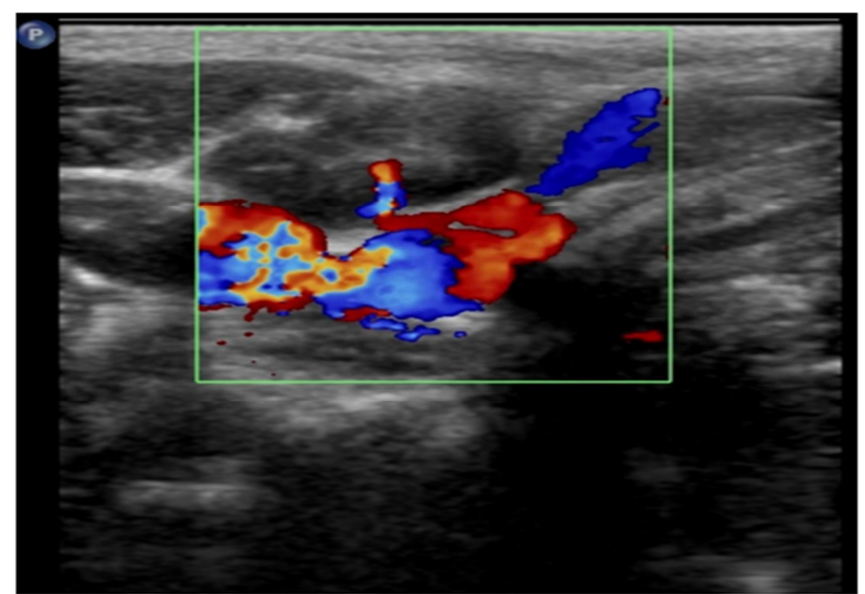

Figure 2: Ultrasound image of neck with color Doppler - shows enlarged cervical nodes anterior to neck vessels. 


\section{Discussion}

Mesenteric adenitis is common among pediatric age group. ${ }^{[1,9]}$ The most affected age group in our study was 7$12 \mathrm{yrs}$, which made up $68 \%$. Peak incidence of mesenteric lymphadenitis was around $65 \%$ in the age group of $5-10$ years, according to Maheshwari et al. ${ }^{[22]}$ According to Gorden et al acute mesenteric lymphadenitis occurs most commonly between 3 to 15 years of age. ${ }^{[13]}$ Peak incidence according to Sikorska et al is 9 years. ${ }^{[19]}$

Males were affected more frequently compared to females, $75.4 \%$ and $24.5 \%$ respectviely, in the study conducted by Maheshwari et al. Similar results were published by Aird I and Sikorska et al also. ${ }^{[19,20]}$ In our study $64 \%$ of the affected children were males, while $36 \%$ happened to be females.

Pain abdomen was the commonest symptom in our study, accounting for $60.5 \%$ i.e., 104 cases out of 172. Pain abdomen was also the most frequent symptom in the study conducted by Maheshwari et al, accounting for $59.6 \%$ of the cases. ${ }^{[22]}$ Wiersma, et al has reported 13 cases of mesenteric lymphadenitis presenting as acute abdomen. ${ }^{[15]}$ In the study conducted by Toorenvliet et al, mesenteric adenitis was the second commonest cause of abdominal pain. ${ }^{[9]}$ Sikorska et al study shows pain abdomen was seen in $49.6 \%$ of cases. ${ }^{\text {[19] }}$ According to Shakya et al mesenteric lymphadenitis was the cause of pain abdomen in $5.1 \%$ of children. ${ }^{[21]}$

In our study upper respiratory tract infection was the second most common presenting symptom affecting $37.2 \%$ of the patients i.e., 64 patients. Similarly $36.8 \%$ of patients had respiratory tract infection in the study conducted by Maheshwari et al. Fever was the third most common presenting symptom in our study $(18.6 \%)$ followed by diarrhea $(6.4 \%)$ and urinary tract symptoms $(3.5 \%)$. Study by Sikorska et al shows that the most common cause of mesenteric lymphadenitis was acute diarrhea in $15.7 \%$ of cases and respiratory tract infection accounted for $14.9 \%$ of cases.

Total of 55cases $(67.9 \%)$ of patients in our study, who presented with upper respiratory tract symptoms, had cervical adenopathy while only 17 cases with upper respiratory tract symptoms had no cervical adenopathy. Two by two table in our study shows confidence interval of $95 \%$, suggesting strong association between mesenteric and cervical adenopathy in patients with upper respiratory tract infection.

\section{Conclusion}

Non-specific mesenteric adenitis is common in pediatric age group and presents as pain abdomen in most of the cases. Ultrasound is a useful tool in diagnosing mesenteric adenitis and preventing unwanted appendicectomy. Upper respiratory tract infection is second most common symptom associated with mesenteric adenitis and is associated with cervical adenopathy. Ultrasound screening of neck for cervical nodes in cases of mesenteric adenitis will help the treating physician in identifying the cause and modifying the treatment accordingly.

\section{References}

1. Macari M, Hines J, Balthazar E, Megibow A. Mesenteric adenitis: CT diagnosis of primary versus secondary causes, incidence, and clinical significance in pediatric and adult patients. AJR. 2002 Apr. 178 (4):853-8.

2. Jernigan RW, Wrenn LE. Acute mesenteric lymphadenitis with suppuration: a case report. Annals of surgery. 1962;156:968-71.

3. Adams EW, Olney BM. Mesenteric Lymph adenitis and acute abdomen. Annals of surgery. 1938;107:359-70.

4. Austin WE. Nonspecific mesenteric lymphadenitis. The Canadian Medical association Journal. 1950;62:244-8.

5. Collins CD. Mesenteric lymphadenitis in adolescents simulating appendicitis. The Canadian Medical association Journal. 1936;4022-55.

6. Leung KCA, Sigalet LD. Acute abdominal pain in children. Am Fam Physician. 2003;1:67(11):2321-7.

7. J Pediatr. 1984 May;104(5):725-8. Rapid diagnosis of adenoviral tonsillitis: a prospective clinical study. Ruuskanen O, Sarkkinen H, Meurman O, Hurme P, Rossi T, Halonen P, Hänninen P.

8. Rosanna helbling, Elisa Conficonni, Marina wyttenbach, Cecilia Benetti, Giacomo D.Simonetti et al. Acute non-specific Mesenteric Lymphadenitis: More than "No need for Surgery", BioMed Research International. 2017: 1151-1155

9. Toorenvliet B, Vellekoop A, Bakker R, et al. Clinical differentiation between acute appendicitis and acute mesenteric lymphadenitis in children. Eur J Pediatr Surg. 2011 Mar. 21 (2):120-3.

10. Moore MM, Kulaylat AN, Brian JM, et al. Alternative diagnoses at paediatric appendicitis MRI. Clin Radiol. 2015 Aug. 70 (8):881-9.

11. Sanchez TR, Corwin MT, Davoodian A, Stein-Wexler R. Sonography of abdominal pain in children: appendicitis and its common mimics. J Ultrasound Med. 2016 Mar. 35 (3):627-35.

12. Gross I, Siedner-Weintraub Y, Stibbe S, et al. Characteristics of mesenteric lymphadenitis in comparison with those of acute appendicitis in children. Eur J Pediatr. 2016 Dec 16.

13. Satish K, Parames H, Hemalatha V, Khatib AS. Clinical profile of mesenteric lymph adenitis in children. Http;//www.paediatriconcall.com/for doctor/Conference_abstract/rep.

14. Simanovsky N, Hiller N. Importance of sonographic detection of enlarged abdominal lymph nodes in children. J Ultrasound Med. 2007;26:581-4.

15. Wiersma F, Gijsbers CFM, Holscher HC. Enlarged mesenteric lymph nodes in children with recurrent abdominal pain. https://openacess.leidenuniv.nl //06.pdf

16. Lucey BC, Stuhlfaut JW, Soto JA. Mesenteric lymph nodes seen at imaging: causes and significance. Radiographics. 2005;25:351-65.

17. Fukushima H, Nagasako R, Takeda I. Acute mesenteric lymphadenitis due to yersinia pseudo tuberculosis lacking a virulence plasmid. Journal of clinical microbiology. 1991;29:1271-5.

18. Mcfadden GDF. Mesenteric lymphadenitis and its clinical manifestations: with special reference to its differential diagnosis from appendicitis. The british medical journal. 1927;24:1174-7.

19. Sikorska-Wisniewska G, Leberek A, Gebka MG. Mesenteric Lymphadenopathy- a valid health problem in children. Med WiekuRozwoj. 2006;10:453-62.

20. Aird I. Acute non- specific mesenteric lymph adenitis. British medical journal. 1945;17:680-2.

21. Shakya KN, Dongol UMS, Khadka SB. A study of abdominal pain in children. JNMA. 2008;47:193-6.

22. Maheshwari K, Lalitha wadhwa.Clinical profile and causes of Mesenteric lymphadenitis in Children. International journal of contemporary Pediatrics. 2016 May; 3(2):550-552. 
Copyright: ( $\odot$ the author(s), publisher. Asian Journal of Medical Radiological Research is an Official Publication of "Society for Health Care \& Research Development". It is an open-access article distributed under the terms of the Creative Commons Attribution Non-Commercial License, which permits unrestricted non-commercial use, distribution, and reproduction in any medium, provided the original work is properly cited.

How to cite this article: Murthy N, Raman R. Non-Specific Mesenteric Lymphadenitis and Cervical Lymphadenopathy in Pediatric Age Group - A Correlative Study. Asian J. Med. Radiol. Res. 2018;6(1):22-25.

DOI: dx.doi.org/10.21276/ajmrr.2018.6.1.6

Source of Support: Nil, Conflict of Interest: None declared. 